\title{
Dynamic Recrystallization Behavior of TA15 Titanium Alloy under Isothermal Compression during Hot Deformation
}

\author{
Yuanxin Luo, Yuqing Heng, Yongqin Wang, and Xingchun Yan \\ State Key Lab of Mechanical Transmission, Chongqing University, Chongqing 400044, China \\ Correspondence should be addressed to Yuanxin Luo; yxluo@cqu.edu.cn
}

Received 13 June 2014; Revised 28 August 2014; Accepted 31 August 2014; Published 19 October 2014

Academic Editor: Rui Vilar

Copyright (C) 2014 Yuanxin Luo et al. This is an open access article distributed under the Creative Commons Attribution License, which permits unrestricted use, distribution, and reproduction in any medium, provided the original work is properly cited.

\begin{abstract}
In order to improve the understanding of the dynamic recrystallization (DRX) behaviors of TA15 titanium alloy (Ti-6Al-2Zr-1Mo$1 \mathrm{~V}$ ), a series of experiments were conducted on a TMTS thermal simulator at temperatures of $1173 \mathrm{~K}, 1203 \mathrm{~K}, 1223 \mathrm{~K}$, and $1273 \mathrm{~K}$ with the strain rates of $0.005 \mathrm{~s}^{-1}, 0.05 \mathrm{~s}^{-1}, 0.5 \mathrm{~s}^{-1}$, and $1 \mathrm{~s}^{-1}$. By the regression analysis for conventional hyperbolic sine equation, the activation energy of DRX in $(\alpha+\beta)$ two-phase region is $Q_{S}=588.7 \mathrm{Kg} / \mathrm{mol}$ and in $\beta$ region is $Q_{D}=225.8 \mathrm{Kg} / \mathrm{mol}$, and a dimensionless parameter controlling the stored energy was determined as $Z / A=\dot{\varepsilon} \exp \left[\left(588.7 \times 10^{3}\right) / R T\right] / 6.69 \times 10^{26}$ in $(\alpha+\beta)$ two-phase region and as $Z / A=\dot{\varepsilon} \exp \left[\left(225.8 \times 10^{3}\right) / R T\right] / 5.13 \times 10^{11}$ in $\beta$ region. The DRX behaviors of TA15 titanium alloy were proposed on the strength of the experiment results. Finally, the theoretical prediction results of DRX volume fraction were shown to be in agreement with experimental observations.
\end{abstract}

\section{Introduction}

The near $\alpha$-type titanium alloy, Ti-6Al-2Zr-1Mo-1V (TA15 titanium alloy), with high specific strength, good creep resistance and corrosion resistance, good thermal stability, and excellent welding performance, has been widely used in aerospace industry [1-3]. However, it is difficult to form the components with complexity in shape and high quality due to its large deformation resistance and low ductility; it is well known that suitable flow stress and dynamic recrystallization (DRX) model is necessary to describe the property of billet [4]. There are several models that have been reported to express the flow stress and the evolution of dynamic recrystallization of alloy. The constitutive model proposed by Sellars and Tegart has been widely used for describing flow behaviors of the metal alloys $[5,6]$. The DRX model mainly contains recrystallization kinetics and grain growth kinetics dynamic. The recrystallization kinetics includes the peak strain equation and dynamic recrystallization fraction equation, while the grain growth kinetics dynamic can be described by recrystallization grain size equation [7]. The Johnson-Mehl-Avrami-Kolmogorov (JMAK) microhardness model was proposed by Kalu et al. to quantify the kinetics of restoration mechanisms in inhomogeneous microstructure [8]. The DRX kinetics model was proposed based on Avrami function to study the dynamic recrystallization for metal alloy $[9,10]$. For titanium alloy, the Sellars-Tegart model $[11,12]$ and the JMAK equation are widely used to express peak stress and the dynamic recrystallization evolution [8].

In this paper, the hot deformation behavior of TA15 titanium was studied for investigating the effects of temperature and strain rate on the flow behaviors. Then, the constitutive equation and DRX kinetic model are obtained to characterize the deformation behavior in the isothermal compression. Finally, the theoretical prediction results of DRX volume fraction were shown to be in agreement with experimental observations.

\section{Experimental Procedure}

Hot compression TA15 titanium alloy bar used in the experiments was with the chemical composition given in Table 1. Titanium and titanium alloys have the characteristics of allotrope change and TA15 titanium alloy includes bodycentered cubic structure $\beta$-phase and close-packed hexagonal structure $\alpha$-phase and $\alpha^{\prime}$-phase. The $\alpha$-phase trends to 
TABLE 1: The chemical composition of as-received TA15 titanium alloy (wt.\%).

\begin{tabular}{rccccccr}
\hline $\mathrm{Al}$ & $\mathrm{Mo}$ & $\mathrm{V}$ & $\mathrm{Zr}$ & $\mathrm{Fe}$ & $\mathrm{C}$ & $\mathrm{N}$ & $\mathrm{Ti}$ \\
\hline 6.3 & 1.32 & 1.68 & 1.9 & 0.04 & 0.01 & 0.01 & $\mathrm{Bal}$ \\
\hline
\end{tabular}

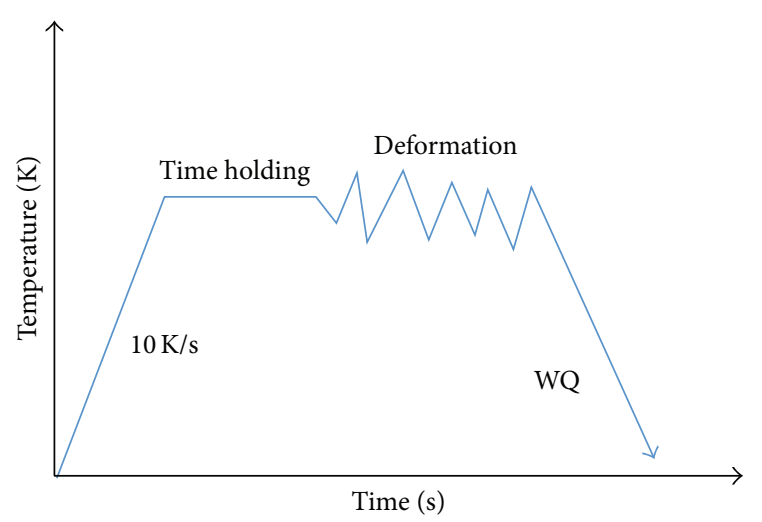

FIGURE 1: The general isothermal loading route.

transform into $\beta$-phase with the increasing of temperature [3]. Its phase transition point is between $1243 \mathrm{~K}$ and $1253 \mathrm{~K}$ [13].

Prior to executing the experiments, the specimens were resistance heated to deformation temperatures with heating ratio of $10 \mathrm{~K} / \mathrm{s}$ and homogenized for $180 \mathrm{~s}$. Cylindrical specimens with a height of $12 \mathrm{~mm}$ and a diameter of $8 \mathrm{~mm}$ were prepared for hot compression tests which were conducted on a TMTS thermal simulation machine at temperatures of $1173 \mathrm{~K}, 1203 \mathrm{~K}, 1223 \mathrm{~K}$, and $1273 \mathrm{~K}$ and at strain rates of $0.005 \mathrm{~s}^{-1}, 0.05 \mathrm{~s}^{-1}, 0.5 \mathrm{~s}^{-1}$, and $1 \mathrm{~s}^{-1}$. The specimens were compressed to $60 \%$ reduction and then quenched in water immediately. The general isothermal loading schedule with different temperature route is shown in Figure 1.

\section{Results and Discussion}

3.1. Flow Stress Behavior. A series of typical true stress-true strain curves obtained during hot compression of homogenized TA15 titanium alloy at different strain rates and deformation temperatures are presented in Figure 2.

It can be easily observed from the true stress-strain curves that the flow stresses increase rapidly to their own peak points. Then the stress decreases slowly and tends to be a constant with the increases of strain. It indicates that the DRX is the dominant softening mechanism under the test conditions. The true stress-strain curves displayed that the work-hardening and softening mechanism vary with strain rate and deformation temperature, which showed that the flow behavior is the conclusion of the dynamic recrystallization and dynamic recovery against work-hardening in isothermal hot compression tests of TA15 titanium alloy. The stress decreases with the increase of deformation temperature at the same strain rate and with the decrease of strain rate under the same deformation temperature. It indicates that the flow stress of TA15 titanium alloy is extremely sensitive to strain rates and deformation temperature.

3.2. Constitutive Equations for Flow Behavior with DRX. In order to further investigate the combined effect of temperature and deformation rate on the deformation behavior, it is necessary to study the constitutive characteristics of titanium alloy represented by the Zener-Hollomon parameter, $Z$, in the exponent-type equation [14-16]:

$$
\begin{aligned}
& Z=\dot{\varepsilon} \exp \left(\frac{Q}{R T}\right), \\
& \dot{\varepsilon}=A_{1} \sigma^{n}\left(-\frac{Q}{R T}\right), \\
& \dot{\varepsilon}=A_{2} \exp (\alpha n \sigma) \exp \left(-\frac{Q}{R T}\right), \\
& \dot{\varepsilon}=A[\sin h(\alpha \sigma)]^{n} \exp \left(-\frac{Q}{R T}\right),
\end{aligned}
$$

where $\dot{\varepsilon}$ is the strain rate $\left(\mathrm{s}^{-1}\right), R$ is the universal gas constant $(8.314 \mathrm{~J} / \mathrm{mol} \times \mathrm{K}), T$ is the absolute temperature $(\mathrm{K}), Q$ is the activation energy for hot deformation ( $\mathrm{J} / \mathrm{mol}), A_{1}, A_{2}, A, \alpha$, and $n$ are material constants, and $\sigma$ is the flow stress (MPa).

3.2.1. Calculation of Material Constants $n$ and $\alpha$. The power law equation (2) represents low stress, the exponential law (3) is preferred for high stress, and the hyperbolic sine law (4) can be suitable for a wide range of stresses [15]. Taking the natural logarithms on both sides of (2) and (3), we can obtain

$$
\begin{gathered}
\ln \dot{\varepsilon}=\ln A_{1}+n \ln \sigma-\frac{Q}{R T}, \\
\ln \dot{\varepsilon}=\ln A_{2}+\alpha n \sigma-\frac{Q}{R T} .
\end{gathered}
$$

It can be easily derived that $n$ and $\alpha$ can be obtained from the slope of the lines $\ln \sigma-\ln \dot{\varepsilon}$ and $\sigma-\ln \dot{\varepsilon}$ plots, respectively. Substituting measured flow stress of TA15 thermal deformation at different temperatures given in Table 2 into (6) and (7), the experimental data and regression results of $\ln \sigma-\ln \dot{\varepsilon}$ and $\sigma-\ln \dot{\varepsilon}$ plots are shown in Figures 3 and 4 :

$$
\begin{gathered}
n=\frac{\partial \ln \dot{\varepsilon}}{\partial \ln \sigma}, \\
\alpha n=\frac{\partial \ln \dot{\varepsilon}}{\partial \sigma} .
\end{gathered}
$$

Under different temperatures (1173-1273) K, the mean value of all the slope rates is accepted as the inverse of material constants $n$ and $\alpha$. The value of $n$ obtained by linear dependent coefficients is 4.59. Figures 5 and 6 show $\alpha n$ obtained through the linear regression data is 0.01855 and the value of $\alpha$ is 0.004 . 

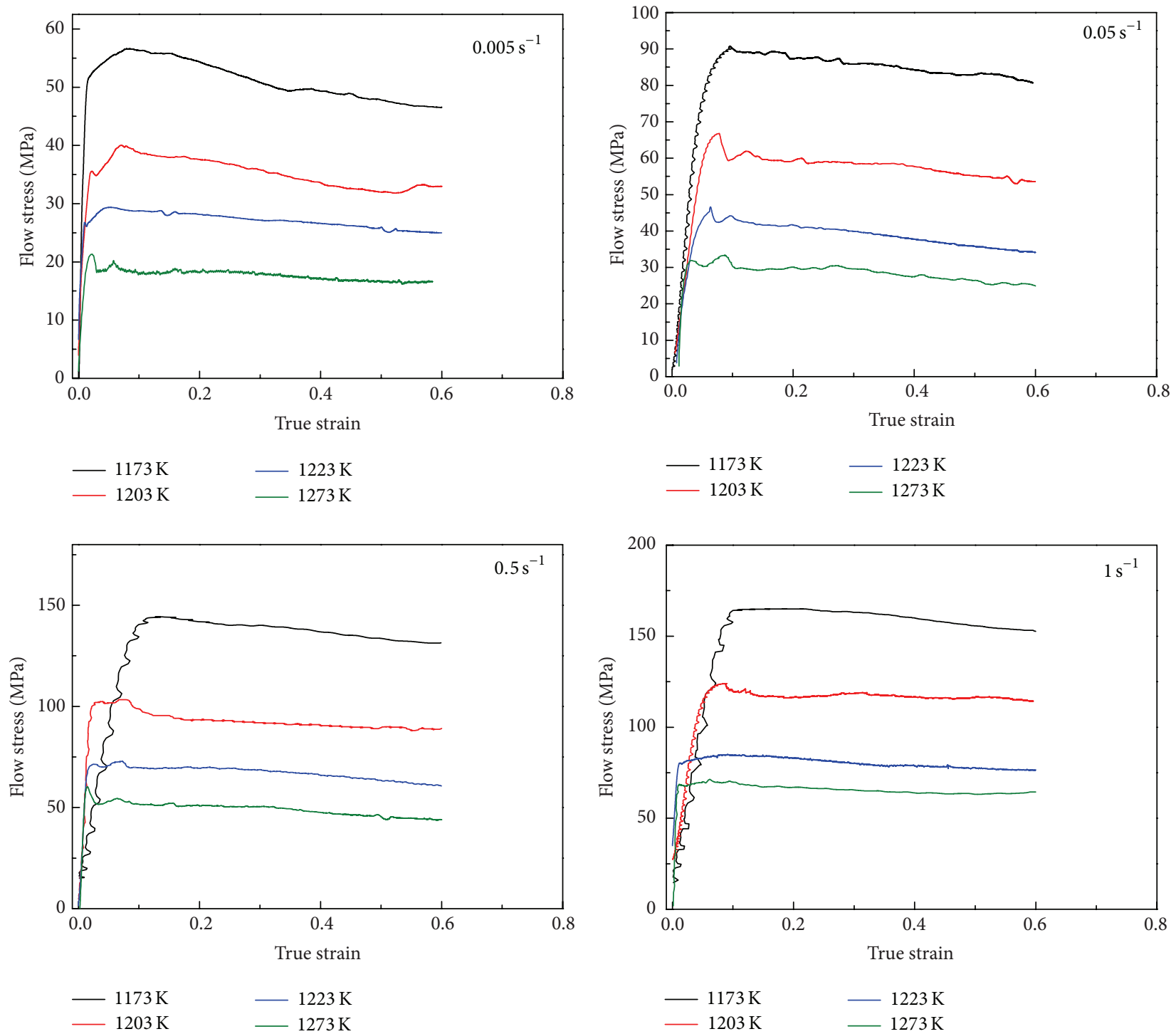

FIgURE 2: The true stress-strain curves of TA15 titanium alloy at different strain rates.

TABLE 2: Peak stress of TA15 stress-strain curves for different temperatures and strain rates.

\begin{tabular}{lcccc}
\hline $\begin{array}{l}\text { Strain rate } \\
\left(\mathrm{s}^{-1}\right)\end{array}$ & \multicolumn{4}{c}{ Deformation temperature $(\mathrm{K})$} \\
\hline 0.005 & 55.926 & 40.186 & 26.713 & 22.019 \\
0.05 & 91.980 & 66.536 & 44.411 & 36.644 \\
0.5 & 148.101 & 108.832 & 73.411 & 60.749 \\
1 & 169.71 & 125.647 & 85.212 & 70.622 \\
\hline
\end{tabular}

3.2.2. Calculation of DRX Activation Energy Q. Taking the natural logarithms on both sides of (4), it can be rewritten as follows:

$$
\ln \dot{\varepsilon}=\ln A+n \ln [\sinh (\alpha \sigma)]-\frac{Q}{R T}
$$

TABLE 3: The value of $\ln [\sinh (\alpha \sigma)]$ at different deformation conditions of TA15.

\begin{tabular}{lcccc}
\hline \multirow{2}{*}{ Strain rate $/ \mathrm{s}^{-1}$} & \multicolumn{4}{c}{ Temperature/K } \\
& 1173 & 1203 & 1223 & 1273 \\
\hline 0.005 & -2.428 & -2.234 & -1.824 & -1.489 \\
0.05 & -1.917 & -1.723 & -1.312 & -0.977 \\
0.5 & -1.405 & -1.211 & -0.8 & -0.466 \\
1 & -1.251 & -1.057 & -0.646 & -0.312 \\
\hline
\end{tabular}

For a given strain rate, the apparent activation energy, $Q$, can be calculated as

$$
Q=\left.\left.R \frac{\partial \ln \dot{\varepsilon}}{\partial \ln [\sinh (\alpha \sigma)]}\right|_{T} \frac{\partial\{\ln [\sinh (\alpha \sigma)]\}}{\partial(1 / T)}\right|_{\dot{\varepsilon}}=\mathrm{RNW}
$$

The curves of $\ln [\sinh (\alpha \sigma)]$ versus $1 / T$ are obtained for different strain rates by using the data in Table 3 , as shown 


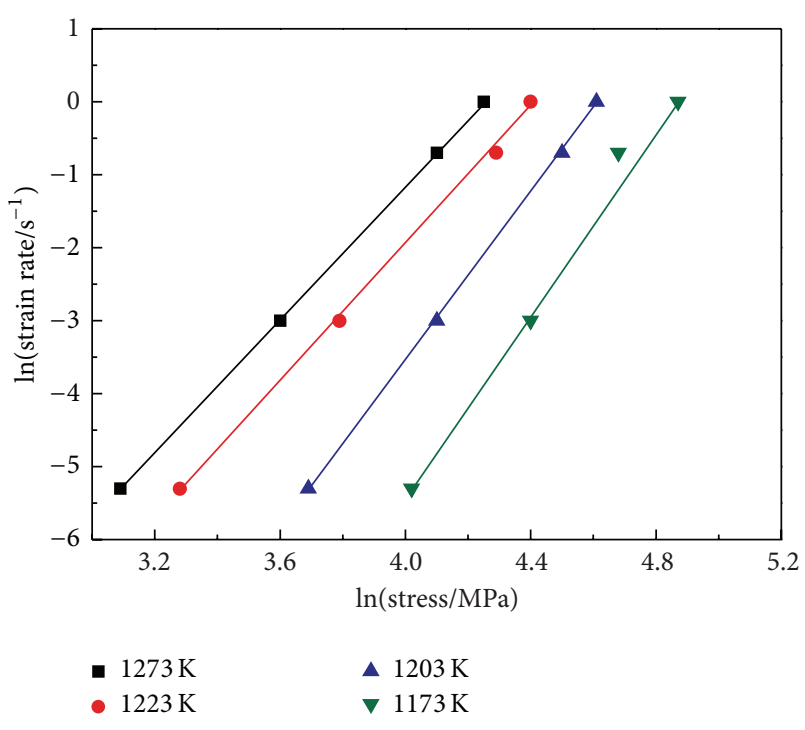

FIGURE 3: The relationships between $\ln \dot{\varepsilon}$ and $\ln \sigma$.

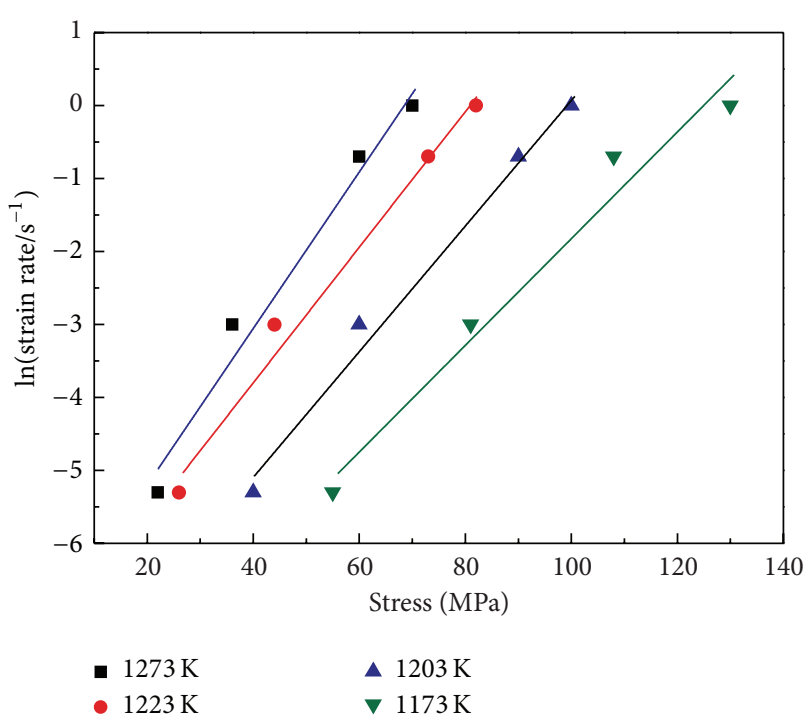

Figure 4: The relationships between $\ln \dot{\varepsilon}$ and $\sigma$.

in Figures 5 and 6. $N$ and $W$ can be approximated by taking the average slope of different strain rate. It is found that the constant of deformation activation energy in $(\alpha+\beta)$ twophase region is $Q_{S}=588.7 \mathrm{Kg} / \mathrm{mol}$ and in $\beta$ region is $Q_{D}=$ $225.8 \mathrm{Kg} / \mathrm{mol}$.

3.2.3. Construction of Constitutive Equation. The equation of flow stress is given in (4), in which the undefined factors $m$, $\alpha, A, n, Q$ can be obtained by using (6), (7), (8), and (9), respectively. Also, it is found that the peak flow stress model in $(\alpha+\beta)$ two-phase region is

$$
\dot{\varepsilon}_{S}=6.69 \times 10^{25}[\sinh (0.004 \sigma)]^{4.59} \exp \left(-\frac{588700}{R T}\right)
$$

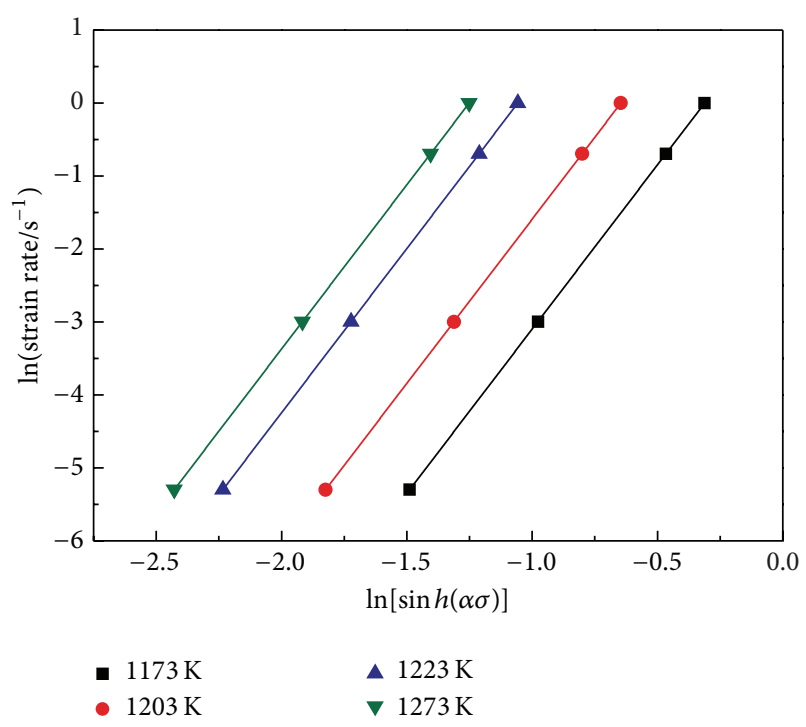

FIgURE 5: The relationships between $\ln \dot{\varepsilon}$ and $\ln [\sinh (\alpha \sigma)]$.

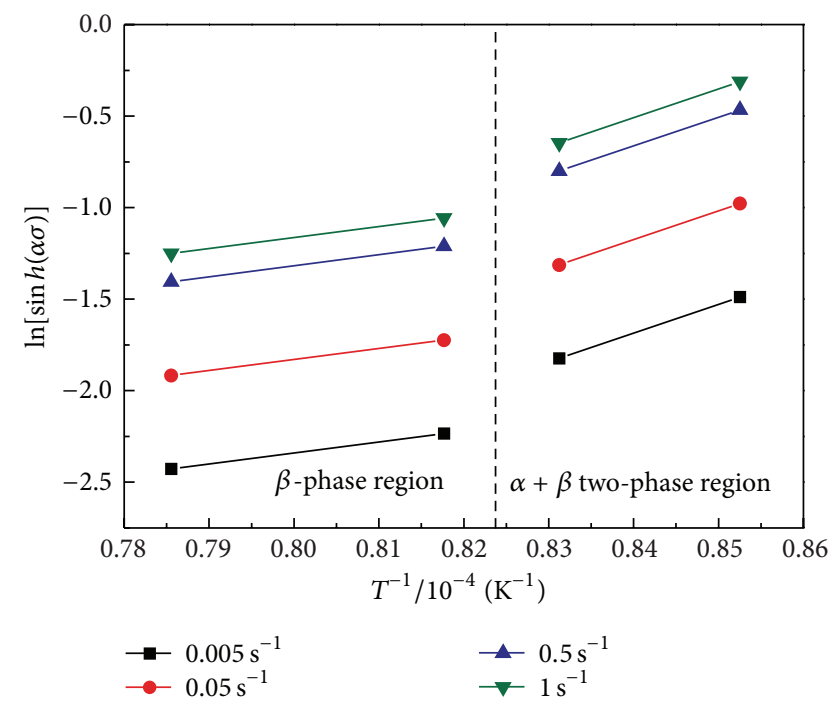

FIgURE 6: The relationships between $\ln [\sinh (\alpha \sigma)]$ and $1 / T$.

and in $\beta$ region is

$$
\dot{\varepsilon}_{D}=5.13 \times 10^{11}[\sinh (0.004 \sigma)]^{4.59} \exp \left(-\frac{225800}{R T}\right) .
$$

Figure 7 displays the result of the relationships between $\ln Z$ and $\ln [\sinh (\alpha \sigma)]$. It follows that the data were divided into two regions, which express single-phase region and twophase region. And the coefficients obtained are presented in this figure.

\subsection{DRX Kinetic Model}

3.3.1. Critical Strain for Initiation of DRX. Based on the previous analysis, the critical strain is necessary to activate the DRX. The critical strains will change for different material 


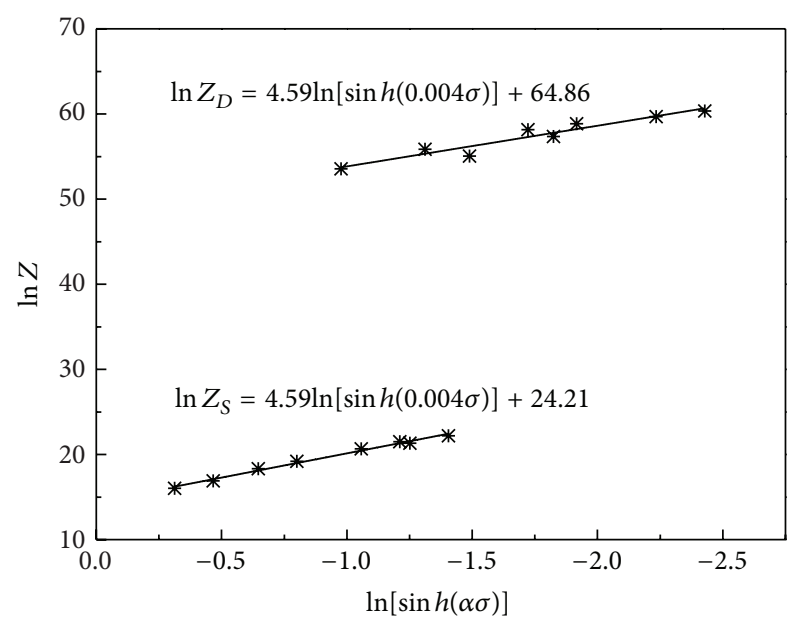

FIGURE 7: The relationships between $\ln Z$ and $\ln [\sinh (\alpha \sigma)]$.

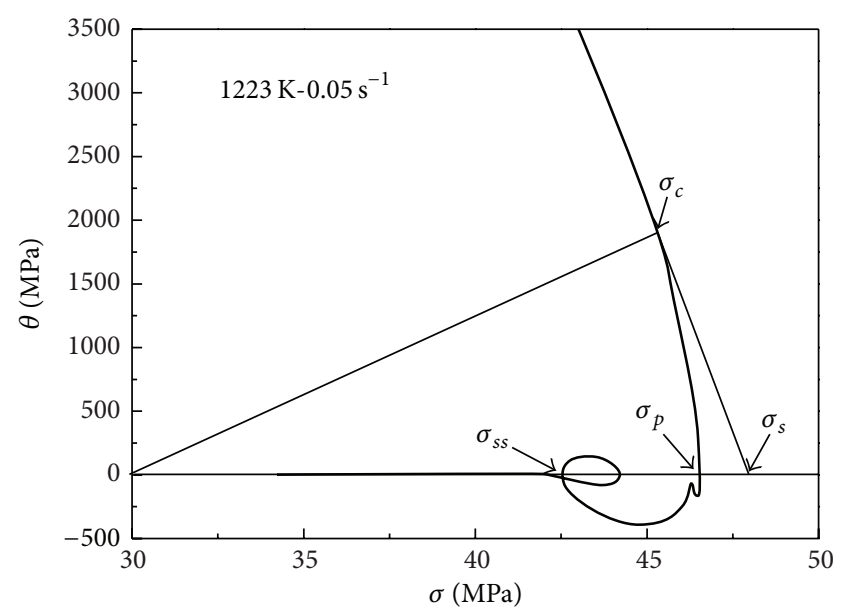

Figure 8: The relationship between hardening and flow stress of TA15.

and deformation conditions. The relationship of critical strain and peak strain can be expressed as $[17,18]$

$$
\varepsilon_{c}=k \varepsilon_{p}
$$

where $\varepsilon_{c}$ is the critical strain, $\varepsilon_{p}$ is the peak strain, and $k$ is material constant. It has been reported that $k$ ranges from 0.65 to 0.85 [19] for metal alloy.

The critical conditions for the onset of DRX are attained when the value of strain hardening rate $\theta=d \sigma / d \varepsilon$ reaches the minimum corresponding to an inflection of $\theta-\sigma$ curve [20]. Figure 8 shows the $\theta-\sigma$ curve of TA15 titanium alloy at the temperature of $1223 \mathrm{~K}$ and with the strain rate of $0.05 \mathrm{~s}^{-1}$. It can be generally divided into three segments. In the first segment, the hardening rate decreases rapidly due to DRV with the increases of $\sigma$ at the beginning of plastic deformation. The reason of this phenomenon is that DRV reduces the effect of dislocation density. The second segment begins from the critical stress $\varepsilon_{c}$ to the peak stress $\varepsilon_{p}$. The subgrain boundary formed with the continuous increase of

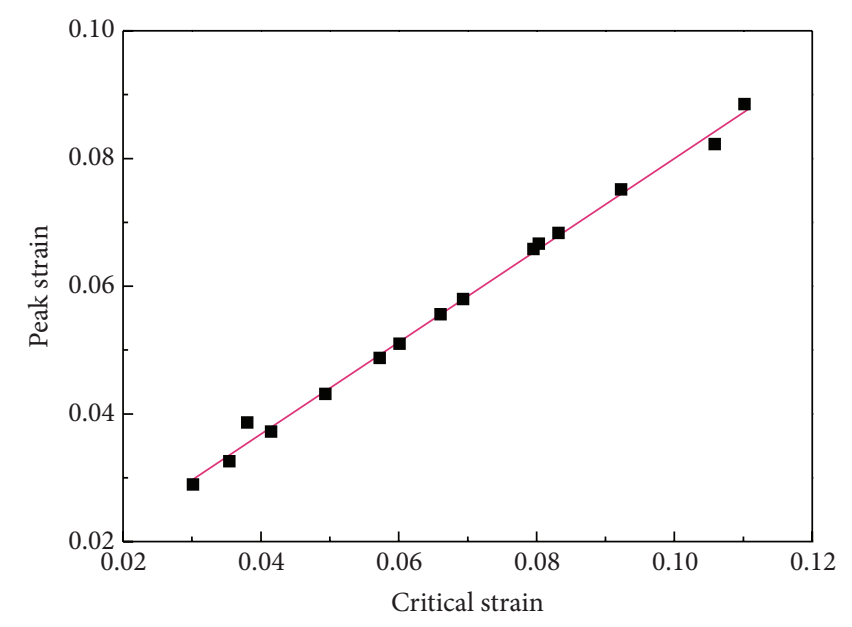

FIGURE 9: The relationships between $\varepsilon_{p}$ and $\varepsilon_{c}$.

dislocation density in this segment, which makes the workhardening rate be still positive but decrease gradually. In the third segment, the $\theta-\sigma$ curve depicts the tendency of falling suddenly due to the occurrence of DRX effect and the value of $\theta-\sigma$ gradually reduces to less than zero and fluctuates up and down and finally keeps a zero value, which express that the continuous DRX occurred. In this stage the value of $\theta$ decreases to zero when the flow stress increases to $\varepsilon_{p}$. This method can be used to determine the relationship between $\varepsilon_{c}$ and $\varepsilon_{p}$. The critical stress can be read from the true stresstrue strain curve after calculating the critical strain. Figure 9 shows the relation of $\varepsilon_{c}$ and $\varepsilon_{p}$ with $k=0.83$. Consequently, the critical strain model of TA15 titanium alloy is $\varepsilon_{c}=0.83 \varepsilon_{p}$.

3.3.2. The Peak Model Strain of DRX. It is of great importance to determine DRX kinetics model due to realization of the softening mechanism in the hot working of alloys. The peak strain value is related to deformation temperature, strain rate, the original grain size, and deformation activation energy. Therefore, the peak strain model is represented as follows [17]:

$$
\varepsilon_{p}=\alpha_{1} d_{0}^{n_{1}} \dot{\varepsilon}^{m_{1}} \exp \left(\frac{Q_{1}}{R T}\right),
$$

where $Q_{1}$ is deformation activation energy; $d_{0}$ is the initial grain size; and $\alpha_{1}, n_{1}, m_{1}$ are material constants. Assume that all of specimens are well heat treated and are with the same grain size. Hence, the influence of the initial grain size on the critical strain is neglectable [21] and (13) can be simplified as

$$
\varepsilon_{p}=\alpha_{1} \dot{\varepsilon}^{m_{1}} \exp \left(\frac{Q_{1}}{R T}\right) .
$$

Taking the logarithm on both sides of (14), it can be rewritten as

$$
\ln \varepsilon_{p}=\ln \alpha_{1}+m_{1} \ln \dot{\varepsilon}+\frac{Q_{1}}{R T} .
$$

From (14), the factor of $m_{1}$ and $Q_{1}$ can take the average of the slopes of $\ln \dot{\varepsilon}-\ln \varepsilon_{p}$ (as shown in Figure 10) and $T^{-1}-$ 


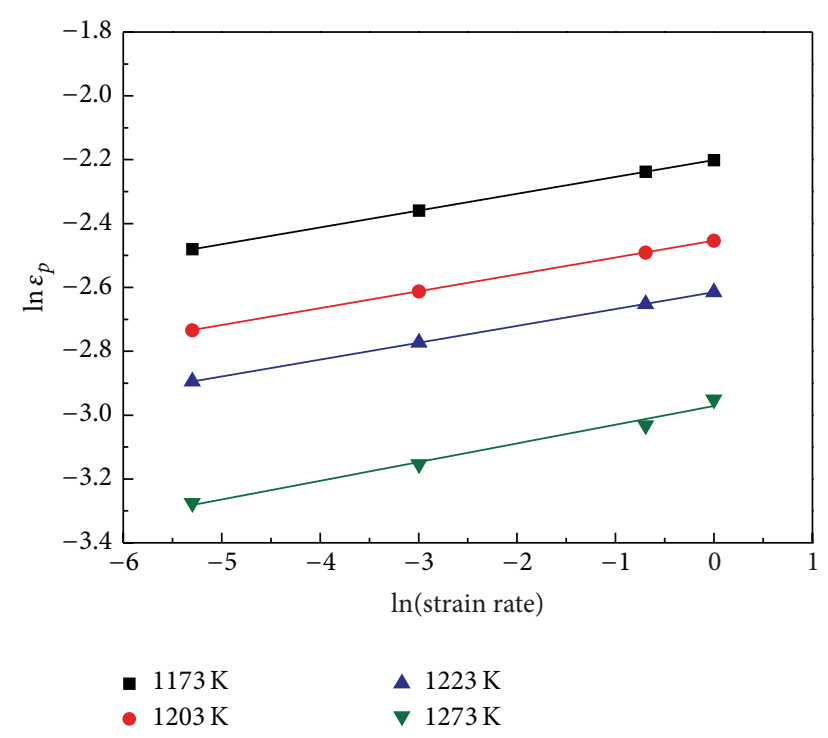

FIgURE 10: The relationships between $\ln \varepsilon_{p}$ and $\ln \dot{\varepsilon}$.

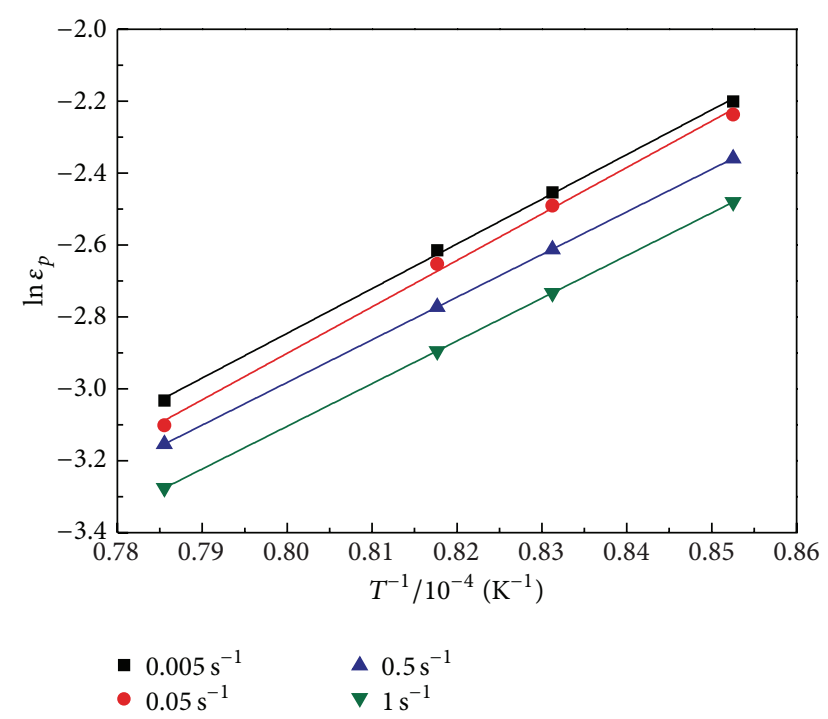

FIGURE 11: The relationships between $\ln \varepsilon_{p}$ and $T^{-1}$.

$\ln \varepsilon_{p}$ (as shown in Figure 11), respectively. We can get $m_{1}=$ $0.05281 ; Q_{1}=98754.78 \mathrm{~J} / \mathrm{mol} . \alpha_{1}$ is then obtained by using (13), $\alpha_{1}=4.429 \times 10^{-6}$.

Consequently, the peak strain model of TA15 titanium alloy is as follows:

$$
\varepsilon_{p}=4.429 \times 10^{-6} \dot{\varepsilon}^{0.0528} \exp \left(\frac{98754.78}{R T}\right)
$$

3.3.3. Models for the Strain for 50\% DRX and DRX Volume Fraction. DRX is a process accompanied by nucleation and growth of grain and a time-dependent process determined on the basis of the DRX kinetics equation. The veracity of DRX kinetics model is connected with the determination of recrystallization fraction, deformation parameters, the dynamic relationship of the process, and the determination of series of parameters of kinematic equation. The relations of DRX kinetics can be described by the JMAK equation as follows [17]:

$$
\begin{gathered}
X_{\mathrm{drx}}=1-\exp \left[-\beta_{d}\left(\frac{\varepsilon-\varepsilon_{c}}{\varepsilon_{0.5}}\right)^{k_{d}}\right], \\
\varepsilon_{0.5}=\alpha_{2} d_{0}^{n_{2}} \dot{\varepsilon}^{m_{2}} \exp \left(\frac{Q_{2}}{R T}\right),
\end{gathered}
$$

where $X_{\mathrm{drx}}$ is the DRX fraction, $\varepsilon_{0.5}$ is the strain for $50 \%$ DRX, $Q_{2}$ is DRX activation energy, and $\beta_{d}, k_{d}, \alpha_{2}, n_{2}, m_{2}$ are material constants.

It is difficult to determine the recrystallized fraction under different deformation conditions based on the microstructures. However, it can be indirectly calculated from the stress-strain curves by using the following equation $[6,12]$ :

$$
X_{\mathrm{drx}}=\frac{\sigma-\sigma_{p}}{\sigma_{s}-\sigma_{p}}
$$

where $\sigma_{p}$ is the peak stress, $\sigma_{s}$ is the steady-state stress, and $\sigma_{p}$ and $\sigma_{s}$ can be calculated from true stress-true strain curves. The DRX fractions of different conditions are calculated by using (19). By substituting (19) into (17), it can be rewritten in logarithm form:

$$
\ln \left[-\ln \left(1-X_{\mathrm{drx}}\right)\right]=\ln \beta_{d}+k_{d} \ln \left(\frac{\varepsilon-\varepsilon_{c}}{\varepsilon_{0.5}}\right)
$$

The stress of 50\% DRX can be calculated by using (19), and then the $\varepsilon_{c}$ can be easily found in the true stress-strain curve. By substituting $\varepsilon_{0.5}, \mathrm{X}_{\mathrm{drx}}$, and $\varepsilon_{c}$ into (20), it is obtained that $\beta_{d}=0.693$ and $k_{d}=1.502$. The DRX fraction of TA15 titanium alloy can be obtained as follows:

$$
X_{\mathrm{drx}}=1-\exp \left[-0.693\left(\frac{\varepsilon-\varepsilon_{c}}{\varepsilon_{0.5}}\right)^{1.502}\right] .
$$

Taking natural logarithm of (18), we can get

$$
\ln \varepsilon_{0.5}=\ln \alpha_{2}+n_{2} \ln d_{0}+m_{2} \ln \dot{\varepsilon}+\frac{Q_{2}}{R T} .
$$

The materials constants can be calculated by using (22): $m_{2}=0.045, Q_{2}=39063.5 \mathrm{~J} / \mathrm{mol}, \alpha_{2}=6.295 \times 10^{-3}$, and $n_{2}=0$ for ignoring the effect of initial grain size. Finally, we can get the strain of $50 \%$ DRX:

$$
\varepsilon_{0.5}=6.295 \times 10^{-3} \dot{\varepsilon}^{0.045} \exp \left(\frac{39063.5}{R T}\right)
$$



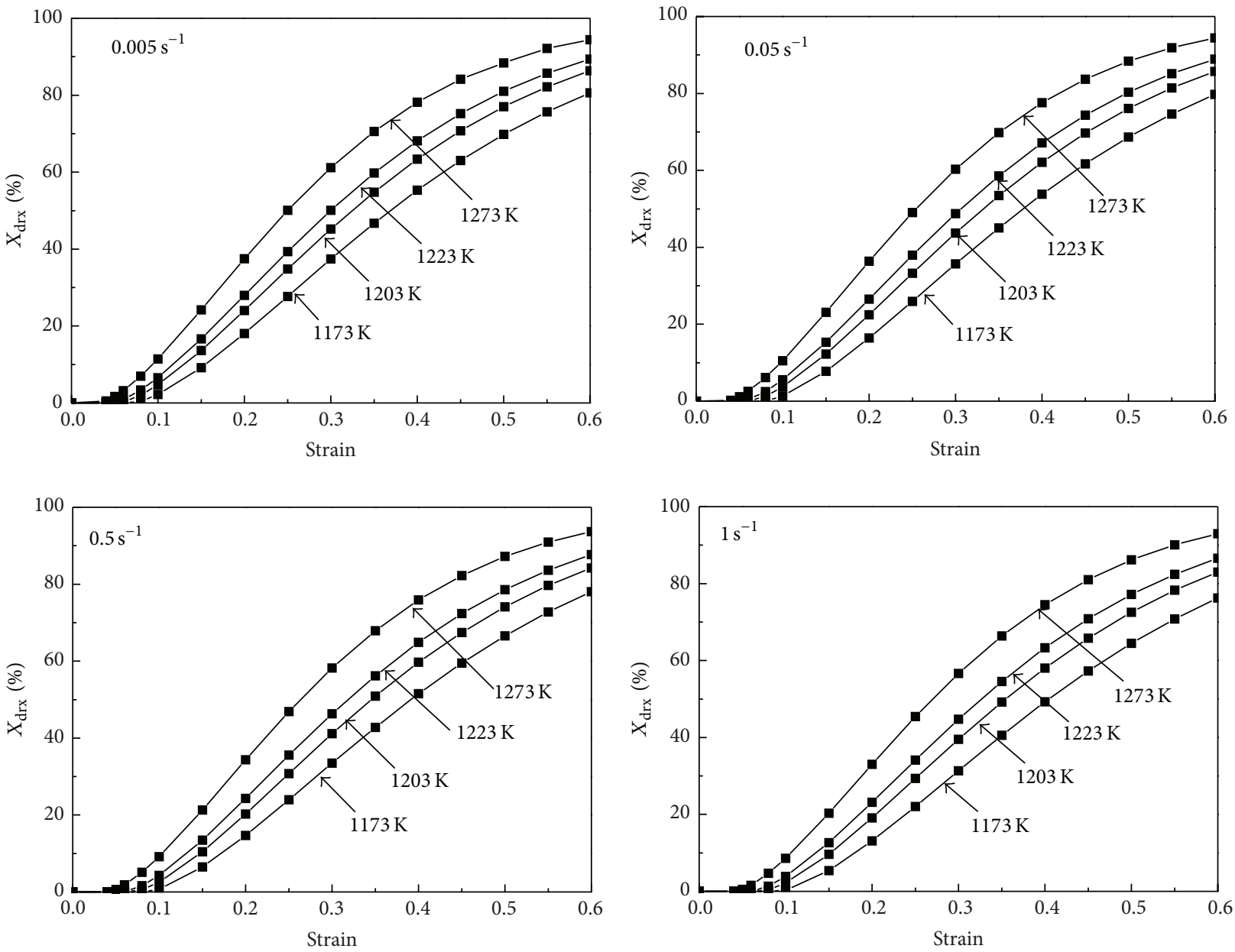

FIGURE 12: Predicted DRX volume fractions of TA15 at different conditions.

Summarily, the DRX kinetics equations of TA15 can be represented as

$$
\begin{aligned}
\varepsilon_{p} & =4.429 \times 10^{-6} \dot{\varepsilon}^{0.0528} \exp \left(\frac{97854.78}{R T}\right), \\
\varepsilon_{c} & =0.83 \varepsilon_{p}, \\
\varepsilon_{0.5} & =6.295 \times 10^{-3} \dot{\varepsilon}^{0.045} \exp \left(\frac{39063.5}{R T}\right), \\
X_{\mathrm{drx}} & =1-\exp \left[-0.693\left(\frac{\varepsilon-\varepsilon_{c}}{\varepsilon_{0.5}}\right)^{1.502}\right] .
\end{aligned}
$$

Based on the calculated results of this model, the effects of strain, strain rate, and deformation temperature on volume fraction of DRX are shown in Figure 12. It can be seen that the curves of volume fraction of DRX appeared as "S" shape and this phenomenon indicates that the volume fraction of DRX grows rapidly between the strain ranges of $0.1-0.45$. The volume fraction of DRX is also slightly affected by the temperature. This is because of the decreased mobility of grain boundaries in a low temperature and high strain rate.
3.4. Microstructure Observations. Typical optical microstructures of TA15 alloy were examined and analyzed on the section plane of specimen deformed to a strain of 0.6 . The microstructures at different temperatures and strain rates are shown in Figure 13. The effects of deformation temperature and strain rate on the microstructures can be seen clearly from these optical micrographs. From Figures 13(a) and 13(b), it can be easily found that the small size grain will be obtained at high strain rate for a given temperature. It means that there is not enough time for the DRX to grow at high strain rate. Conversely, the grain size of DRX is large for the higher temperature, as shown in Figures 13(a) and 13(c).

It can be found clearly that the percentage of $\beta$-phase is higher in Figure 13(d) than that in Figure 13(d). It expresses that there is a tendency of $\alpha \rightarrow \beta$ phase transformation occurring with the increase of temperature. The close-packed hexagonal $\alpha$-phase trends to transform into body-centered cubic $\beta$-phase with the increase of temperature. Because body-centered cubic $\beta$-phase has the features of high stacking fault energy and a large number of slip systems, the flow stress decreases and becomes gently. In the temperature range of $1223 \mathrm{~K}-1273 \mathrm{~K}$, it can be found that the flow stresses are not so 


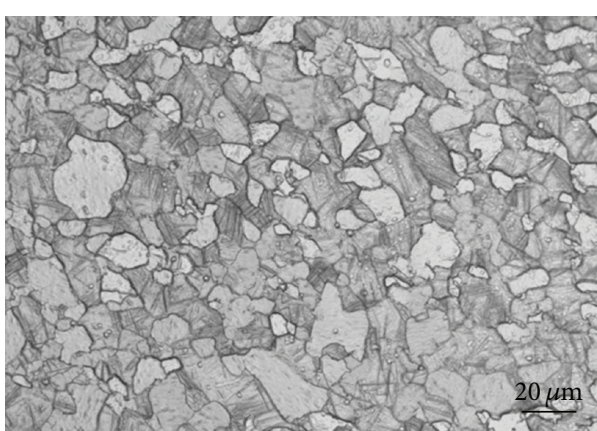

(a)

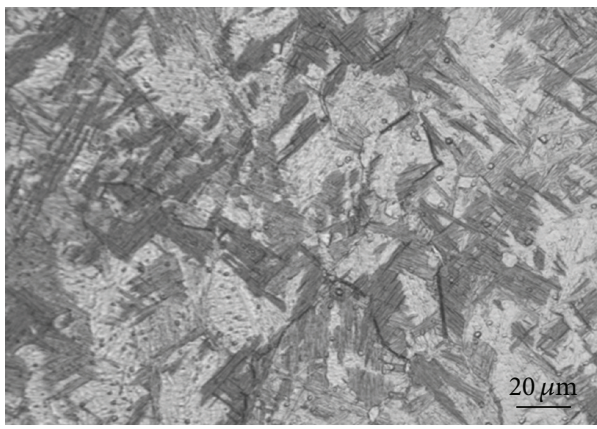

(c)

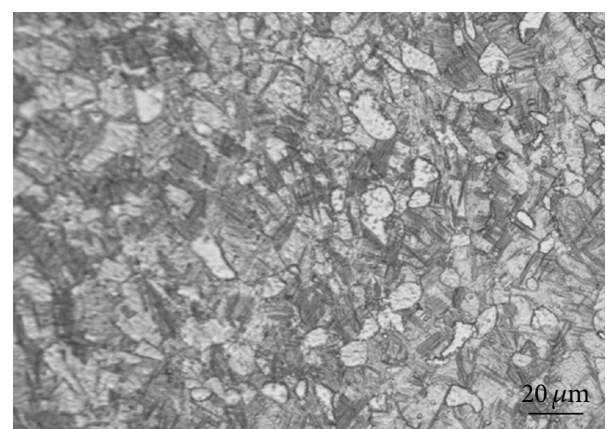

(b)

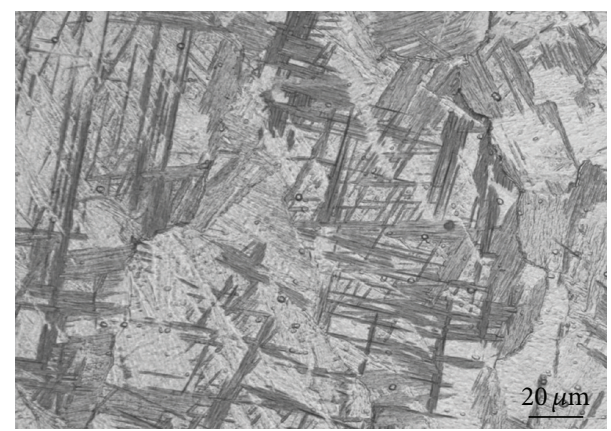

(d)

FIGURE 13: Optical microstructures of TA15 alloy deformed under different conditions: (a) $\mathrm{T}=1203 \mathrm{~K}, \dot{\varepsilon}=0.005 \mathrm{~s}$; (b) $\mathrm{T}=1203 \mathrm{~K}, \dot{\varepsilon}=0.05 \mathrm{~s}^{-1}$; (c) $T=1223 \mathrm{~K}, \dot{\varepsilon}=0.05 \mathrm{~s}^{-1}$; (d) $T=1273 \mathrm{~K}, \dot{\varepsilon}=0.05 \mathrm{~s}^{-1}$.

sensitive to the temperature. So the flow stress drops slightly for the increase of the temperature.

\section{Conclusions}

Hot deformation behavior of TA15 titanium alloy is studied at high temperatures under isothermal compression in this paper. Based on this research, the following conclusions can be drawn.

(1) Through the regression analysis for conventional hyperbolic sine equation, the coefficient of plastic deformation constitutive equation of TA15 titanium alloy during high temperature is calculated, in which the value of deformation activation energy in $(\alpha+\beta)$ two-phase region is $Q_{S}=588.7 \mathrm{Kg} / \mathrm{mol}$ and in $\beta$ region is $Q_{D}=225.8 \mathrm{Kg} / \mathrm{mol}$.

(2) The constitutive equations and DRX kinetic model are obtained by this investigation that can be used to describe the flow behavior of TA15 titanium alloy in hot forming.

(3) The optical microstructure observation of the TA15 specimens deformed to a strain of 0.6 under different conditions verified the influence of deformation conditions on the evolution of DRX volume fraction.

\section{Conflict of Interests}

The authors declare that there is no conflict of interests regarding the publication of this paper.

\section{Acknowledgments}

This research is supported by the National Natural Science Foundation of China (Grant no. 51345013) and the Fundamental Research Funds for the Central Universities (Grant no. CDJZR12110002).

\section{References}

[1] Y. Chen, W.-C. Xu, D.-B. Shan, and B. Guo, "Microstructure evolution of TA15 titanium alloy during hot power spinning," Transactions of Nonferrous Metals Society of China, vol. 21, no. 2, pp. s323-s327, 2011.

[2] L. Huang, R. Zeng, X. Zhang, and J. Li, "Study on plastic deformation behavior of hot splitting spinning of TA15 titanium alloy," Materials \& Design, vol. 58, pp. 465-474, 2014.

[3] S. Zhu, H. Yang, L. G. Guo, and X. G. Fan, "Effect of cooling rate on microstructure evolution during $\alpha / \beta$ heat treatment of TA15 titanium alloy," Materials Characterization, vol. 70, pp. 101-110, 2012.

[4] Q. J. Sun and G. C. Wang, "Microstructure and superplasticity of TA15 alloy," Materials Science and Engineering A, vol. 606, pp. 401-408, 2014. 
[5] Y. C. Lin, M.-S. Chen, and J. Zhong, "Constitutive modeling for elevated temperature flow behavior of 42CrMo steel," Computational Materials Science, vol. 42, no. 3, pp. 470-477, 2008.

[6] Y. Xu, L. Hua, and Y. Sun, "Deformation behaviour and dynamic recrystallization of AZ61 magnesium alloy," Journal of Alloys and Compounds, vol. 580, pp. 262-269, 2013.

[7] X. N. Peng, H. Z. Guo, Z. F. Shi, C. Qin, Z. L. Zhao, and Z. Yao, "Study on the hot deformation behavior of TC4-DT alloy with equiaxed $\alpha+\beta$ starting structure based on processing map," Materials Science and Engineering A, vol. 605, pp. 80-88, 2014.

[8] P. N. Kalu and D. R. Waryoba, "A JMAK-microhardness model for quantifying the kinetics of restoration mechanisms in inhomogeneous microstructure," Materials Science and Engineering $A$, vol. 464, no. 1-2, pp. 68-75, 2007.

[9] J. Liu, Z. Cui, and L. Ruan, "A new kinetics model of dynamic recrystallization for magnesium alloy AZ31B," Materials Science and Engineering A, vol. 529, no. 1, pp. 300-310, 2011.

[10] J. J. Jonas, X. Quelennec, L. Jiang, and É. Martin, “The Avrami kinetics of dynamic recrystallization,” Acta Materialia, vol. 57, no. 9, pp. 2748-2756, 2009.

[11] J. Xiao, D. S. Li, X. Q. Li, and T. S. Deng, "Constitutive modeling and microstructure change of Ti-6Al-4V during the hot tensile deformation," Journal of Alloys and Compounds, vol. 541, pp. 346-352, 2012.

[12] W. Peng, W. Zeng, Q. Wang, and H. Yu, "Comparative study on constitutive relationship of as-cast Ti60 titanium alloy during hot deformation based on Arrhenius-type and artificial neural network models," Materials \& Design, vol. 51, pp. 95-104, 2013.

[13] Z. Sun, S. Guo, and H. Yang, "Nucleation and growth mechanism of $\alpha$-lamellae of Ti alloy TA15 cooling from an $\alpha+\beta$ phase field," Acta Materialia, vol. 61, no. 6, pp. 2057-2064, 2013.

[14] S. F. Medina and C. A. Hernandez, "General expression of the Zener-Hollomon parameter as a function of the chemical composition of low alloy and microalloyed steels," Acta Materialia, vol. 44, no. 1, pp. 137-148, 1996.

[15] Y. Wang, Y. Liu, G. Y. Yang et al., "Hot deformation behaviors of $\beta$ phase containing Ti-43Al-4Nb-1.4W-based alloy," Materials Science and Engineering A, vol. 577, pp. 210-217, 2013.

[16] C. M. Sellars and W. J. McTegart, "On the mechanism of hot deformation," Acta Metallurgica, vol. 14, no. 9, pp. 1136-1138, 1966.

[17] C. Zener and J. H. Hollomon, "Effect of strain rate upon plastic flow of steel," Journal of Applied Physics, vol. 15, no. 1, pp. 22-32, 1944.

[18] M.-S. Chen, Y. C. Lin, and X.-S. Ma, "The kinetics of dynamic recrystallization of 42CrMo steel," Materials Science and Engineering A, vol. 556, pp. 260-266, 2012.

[19] Z. Yang, Y. C. Guo, J. P. Li, F. He, F. Xia, and M. X. Liang, "Plastic deformation and dynamic recrystallization behaviors of Mg5Gd-4Y-0.5Zn-0.5Zr alloy," Materials Science and Engineering A, vol. 485, no. 1-2, pp. 487-491, 2008.

[20] A. I. Fernández, P. Uranga, B. López, and J. M. Rodriguez-Ibabe, "Dynamic recrystallization behavior covering a wide austenite grain size range in $\mathrm{Nb}$ and $\mathrm{Nb}$-Ti microalloyed steels," Materials Science and Engineering A, vol. 361, no. 1-2, pp. 367-376, 2003.

[21] C. M. Sellars, "From trial and error to computer modelling of thermomechanical processing," Ironmaking and Steelmaking, vol. 38 , no. 4, pp. 250-257, 2011. 

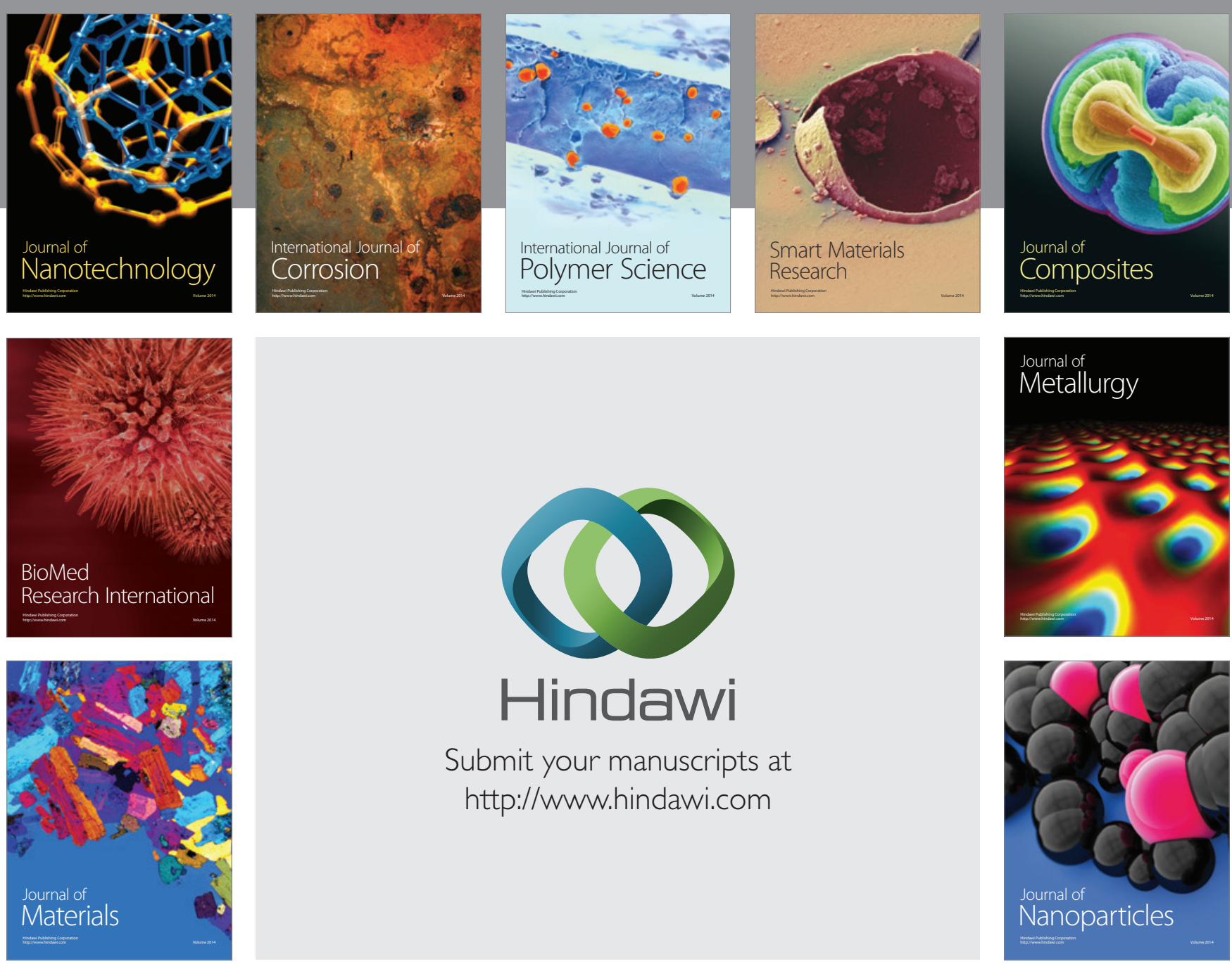

Submit your manuscripts at http://www.hindawi.com
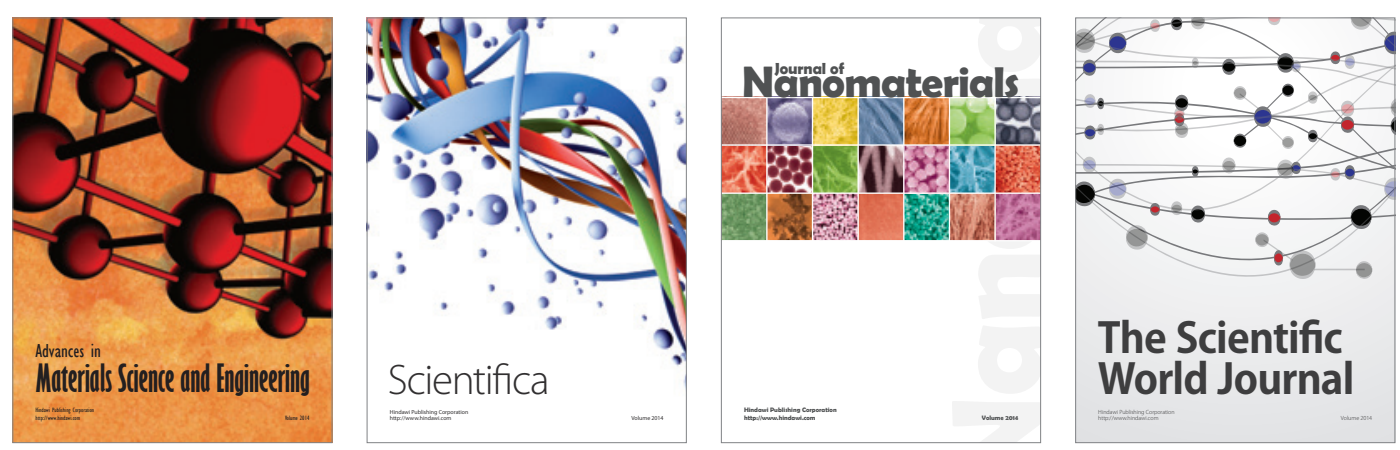

\section{The Scientific World Journal}
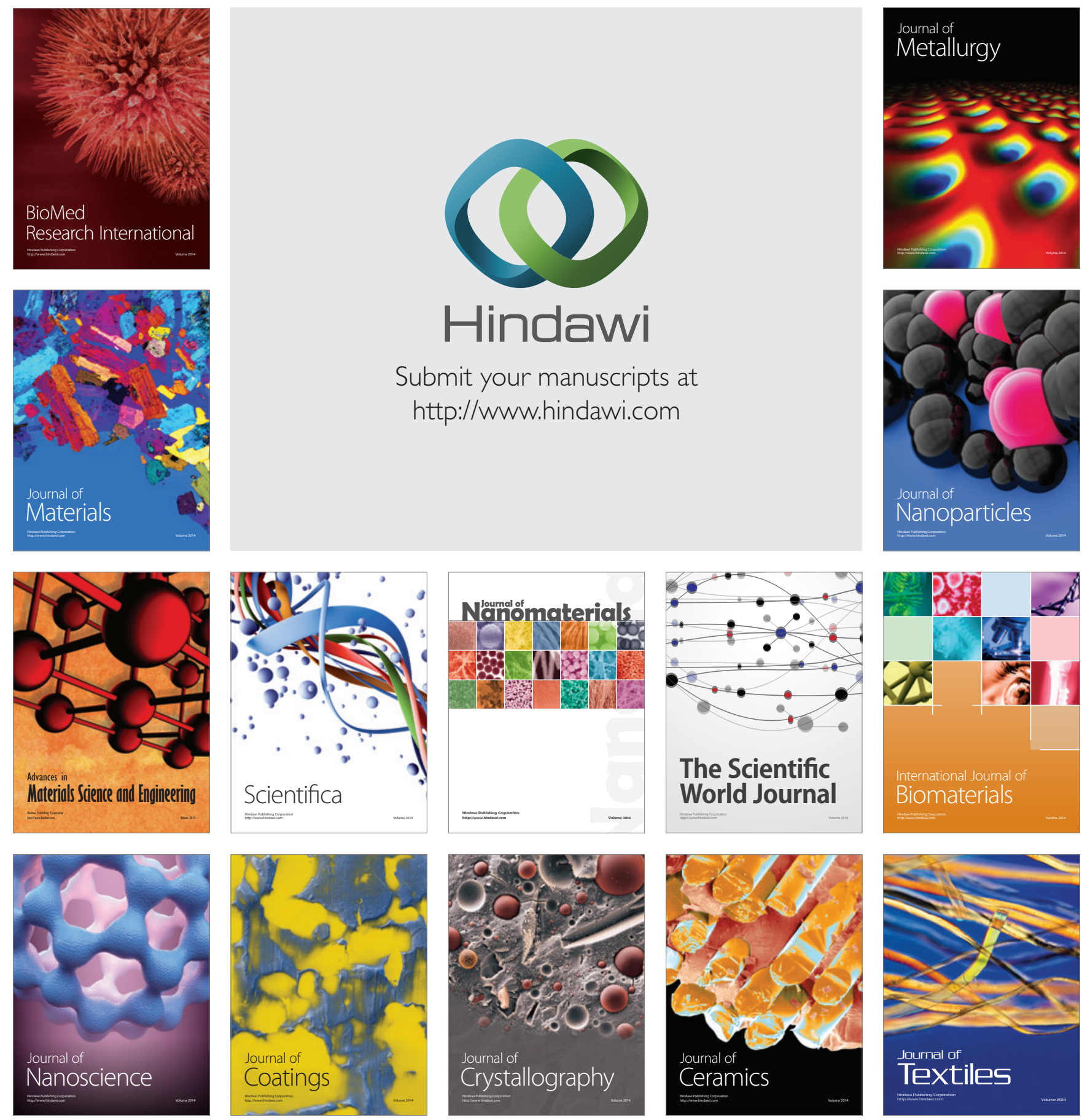